\title{
Successive matching-to-sample in the pigeon: Variations on a theme by Konorski
}

\author{
EDWARD A. WASSERMAN \\ University of Iowa, Iowa City, Iowa 52242
}

\begin{abstract}
In 1959, Konorski proposed a successive matching-to-sample paradigm with which to study short-term memory in animals. Although the technique has been little used, it affords several distinct advantages over more commonly employed matching-to-sample procedures. Konorski's paradigm involves the successive presentation of a pair of discriminative stimuli with a brief interstimulus interval between them. Reinforcement is scheduled to occur only when the second stimulus of a pair matches the first; otherwise, nonreinforcement follows. An investigation of the pigeon's food-reinforced keypecking behavior is reported using a variant of Konorski's technique. Pigeons rapidly learned to differentiate matching and nonmatching stimulus pairs when brief $(5-\mathrm{sec})$ color stimuli were separated by a 1-sec interstimulus interval. No such differentiation arose when control subjects were trained with reinforcement equiprobable on matching and nonmatching trials. No support was found for the notion that correct performance under this successive-matching procedure was due to overt mediating behaviors.
\end{abstract}

A variety of procedures has been used in the study of short-term memory in nonhuman organisms. Research during the first half of this century involved modifications of Hunter's (1913) delayed response procedure (see Fletcher, 1965). More recent research has often made use of the delayed matching-to-sample problem (see Blough, 1959). The delayed matching task involves: (a) the presentation of a sample stimulus for a period of time, terminated either automatically or by the subject's behavior; (b) a delay period, during which no discriminative stimuli are present; and (c) the presentation of the previously presented sample stimulus in addition to one or more test stimuli of the same sensory modality. Choice of the sample stimulus is then followed by reward; choice of any other test stimulus is followed by nonreward and/or punishment.

Although much has been learned about the determinants of short-term memory using the classical delayed matching paradigm (see D'Amato's 1973 review), several features of the procedure render its application to a variety of experimental problems either difficult or impossible. The difficulties are: (1) Because numerous stimuli must be tested at the time of choice, the use of nonvisual stimuli entails special problems. Most obviously, the presentation of two or more sounds or odors raises the potential of interaction between distinctive sensory signals (see Herman \& Gordon, 1974). Indeed, the very possibility of utilizing body orientation

This research was supported in part by Grant MH 24482, awarded to the author by the National institute of Mental Health, and by the Graduate College of The University of lowa. Special thanks go to Don Carr and Jim Deich for their technical assistance and to G. A. Heise for helpful comments. Requests for reprints should be sent to E. A. Wasserman, Department of Psychology, The University of Iowa, Iowa City, Iowa 52242. or flavor stimuli is precluded. (2) Since the numerous stimuli that are simultaneously presented at choice are inevitably located in different places, subjects may adopt position preferences that impede the course of mastery of the task. (3) Incorrect performance may reflect stimulus generalization from other test stimuli at the time of choice, rather than failure to remember the sample stimulus. (4) The discrete character of choice performance in the classical procedure may be less sensitive to experimental manipulations than criterion behaviors that vary continuously. (5) As subjects gradually master the classical matching-to-sample task, the probability of reinforcement correspondingly increases. Changes in performance that are traceable to this procedural variation might affect matching behavior in unknown ways.

A modification of the classical delayed matching-tosample procedure was proposed by Konorski (1959). In several respects $h$ is method rectifies some of the limitations of the classical procedure. This paper describes Konorski's procedure, delineates the behavioral relationships that have been discovered with this technique, and reports the results of an investigation using a variant of Konorski's paradigm.

\section{THE KONORSKI PROCEDURE}

As a means of studying short-term memory, Konorski (1959) proposed that discriminations between different serial compound stimuli might prove especially informative. Suppose that two brief auditory stimuli of high $(\mathrm{H})$ and low $(\mathrm{L})$ pitch are presented in the following orders: L-L, L-H, H-L, and H-H. Also suppose that only trials involving tones of the same pitch are followed by reinforcement ( $\mathrm{L}-\mathrm{L}$ and $\mathrm{H} \cdot \mathrm{H}$ ); trials involving nonmatching tones are never followed by reinforcement (L-H and 
H-L). It can then be seen that either the first or the second stimulus alone conveys insufficient information concerning the availability or unavailability of reinforcement on any given trial; the subject must remember the pitch of the first-presented stimulus if it is to differentiate reinforced and nonreinforced trials. Throughout the course of differential conditioning, measures of the strength of responding during the second-presented stimulus serve as the principal dependent variables.

Investigations in Konorski's laboratory by Chorazyna (1959) and by Chorazyna and Stepien (1961) confirmed that dogs are able to master this memory task. Food reinforcement was made contingent upon a paw placement response during the second of a pair of auditory stimuli. These pure-tone stimuli were each $2 \mathrm{sec}$ in duration and varied from 110 to $1400 \mathrm{~Hz}$; the interstimulus interval between paired stimuli was $3 \mathrm{sec}$; and the intertrial interval ranged from 90 to $120 \mathrm{sec}$. Initially, responding was established to $\mathrm{L}-\mathrm{L}$ and $\mathrm{H}-\mathrm{H}$ tone sequences. Then, $\mathrm{L}-\mathrm{H}$ tone pairs were introduced but were never reinforced. This nonreinforced sequence was scheduled on approximately two of a day's nine total trials. Within 4 months, five of seven animals learned not to respond on L-H trials. Finally, the successful subjects were administered nonreinforced $H-L$ pairs. No transfer of nonresponding from L-H pairs to H-L pairs was evidenced, although the animals were eventually capable of withholding responses on both L-H and H-L trials. Increasing the interstimulus interval beyond 3 or $4 \mathrm{sec}$ led to a general (but unspecified) deterioration in performance.

Generally similar methods and results were used with African Green monkeys (Stepien, Cordeau, and Rasmussen, 1960). Using click stimuli of high and low pulse rates, generalization of nonresponding from H-L click pairs to L-H pairs occurred. Stepien et al. (1960) also observed transfer of the complete discrimination from intermittent auditory stimuli (clicks) to intermittent visual stimuli (flashes). The reason for the transfer of the "matching" rule in this experiment but not in those conducted in Konorski's laboratory remains unknown.

Since these initial investigations, Konorski's successive matching-to-sample procedure has been used rarely. Bradley and Roberts (1965) investigated the logical converse of Konorski's procedure-mismatching. African Green monkeys were trained to panel press to earn banana pellets. Reinforcement was contingent upon pressing a second stimulus whose color differed from the first stimulus, or upon not pressing a second stimulus whose color was the same as the first stimulus. Bradley and Roberts found that a stagewise construction of the problem was necessary for the monkeys to master the task; subjects failed to discriminate matching and nonmatching stimulus pairs when the full problem was introduced immediately after initial response shaping. Subsequent to discrimination mastery, subjects were tested at several interstimulus intervals. The percentage of correct responses declined as the interstimulus interval was lengthened; the average score at an interstimulus interval of $0 \mathrm{sec}$ was $95 \%$, whereas at a delay of $7 \mathrm{sec}$. performance fell to $75 \%$. Further investigation and analysis of performance using the "mismatching" procedure is available in another report by Roberts and Bradley (1967).

More recently, D'Amato and Worsham (1974) studied Capuchin monkeys that were trained under a modified version of Konorski's technique. Rather than requiring subjects to respond or not respond on matching and nonmatching trials, respectively, subjects were trained to make one manipulatory response on matching trials and to make another manipulatory response on nonmatching trials. Under these circumstances, monkeys evidenced little forgetting at interstimulus intervals up to $16 \mathrm{sec}$; at longer delays, however, the percentage of correct responses declined toward chance performance. This modification of Konorski's procedure eliminates the feature, noted by Weiskrantz (1968), that "go" and "nogo" responses are not equally likely; by the proper choice of manipulatory responses, the initial probability of correct and incorrect responses can be equated.

Finally, Urcuioli and Nevin (1975) used a procedure combining elements of the standard matching-to-sample problem and Konorski's successive-matching paradigm. Of greatest importance here was the fact that, after discrimination mastery, pigeons successfully generalized the abstract "matching" principle when first shown novel visual stimuli (also see Zentall \& Hogan, 1974).

\section{EXPERIMENT}

In the hope of learning more about the characteristics of performance under the successive-matching procedure of Konorski, the following experiment with pigeon subjects was conducted. Several procedural and analytical departures were made from Konorski's original investigations in order to promote this aim. First, the stimuli were green $(G)$ and red $(R)$ colored key lights, which are easily discriminated by pigeons and should minimize incorrect performance based upon stimulus generalization. Second, all matching ( $G-G$ and $R \cdot R$ ) and nonmatching (G-R and R-G) stimulus pairs were presented from the inception of training. The intent here was to determine whether the piecemeal construction of the problem used by Bradley and Roberts (1965), Chorazyna (1959), Chorazyna and Stepien (1961), and Stepien et al. (1960) was necessary for the acquisition of the conditional discrimination. Third, in contrast to the earlier investigations that endeavored to minimize responses during the first stimulus of a pair, the present experiment required subjects to respond at least once to the first-presented stimulus, in order to insure that they had oriented their visual receptors toward it; observing responses frequently facilitate the acquisition of difficult discrimina- 
tions (e.g., Siegel, 1969). Finally, in addition to training subjects on the successive-matching procedure, other subjects were trained under a control procedure, wherein the four stimulus pairs (G-G, G-R, R-G, and R-R) were presented just as in the discrimination procedure; but the probability of food reinforcement was the same after all stimulus sequences. This nondiscrimination procedure was designed to control for the possibility that different rates of responding might be generated by matching and nonmatching stimulus pairs (perhaps due to "expectancies" or "searching images") and that nonrandom aspects of the experimental situation, other than the differential stimulus-reinforcer correlations, might be controlling the subjects' behavior (see D'Amato \& O’Neill, 1970).

\section{Method}

Subjects. The subjects were six adult homing pigeons that had prior experience with response-contingent reinforcement schedules. The birds were maintained at $80 \%$ of their freefeeding body weights by limited access to food after daily sessions. The pigeons were individually housed, with grit and water continuously available in the home cages, and tested daily when their weights did not exceed the $80 \%$ value by more than $15 \mathrm{~g}$.

Apparatus. Four three-key pigeon conditioning chambers were used. In each, only the center key was operative. The 1.9$\mathrm{cm}$-diam clear plastic key required a force of at least $5 \mathrm{~g}(.05 \mathrm{~N})$ for activation, and was positioned $9.4 \mathrm{~cm}$ above the solenoidoperated grain magazine and $4.9 \mathrm{~cm}$ below the houselight $(28 \mathrm{~V}$ dc, CM 1820 bulb), which was encased in a black metal housing that directed light toward the ceiling. The pecking key could be transilluminated with either green or red light by means of a miniature display projector (IEE Series $10,28 \mathrm{~V}$ dc, CM 1820 bulbs). The interior walls of the chamber and the response panel (which contained the response keys, houselight, and grain hopper) were constructed of aluminum. Masking noise was continually provided to the experimental room. In an adjoining room, scheduling and data collection were performed by a DEC PDP 8/I computer using the SKED software system (8K papertape run-time version) and a relay interface.

Procedure. As preliminary training, subjects were given a single session of autoshaping training (see Brown \& Jenkins, 1968) to the green and red key lights in order to insure responsivity to the briefly presented stimuli.

Experimental training began the following day and continued for 20 consecutive sessions. Each session comprised 100 trials involving the presentation of the two colored key lights. The first-presented key color was green or red on a random half of the trials and remained on until the first keypeck after $5 \mathrm{sec}$ occurred. Upon termination of the first key color, a 1-sec delay interval ensued during which no stimulus lighted the key and pecks at the key were ineffectual. Then, the key was again illuminated either green or red with equal probability. On reinforced trials, the first keypeck to occur after $5 \mathrm{sec}$ had elapsed extinguished the second-presented key light, resulting in the elevation and illumination of the food hopper and the extinction of the houselight for $2.5 \mathrm{sec}$. On nonreinforced trials, the second-presented stimulus was automatically turned off after $5 \mathrm{sec}$ and was immediately followed by extinction of the houselight for $2.5 \mathrm{sec}$. Intertrial intervals involved house illumination and were 25 sec long.

Two experimental conditions were arranged by scheduling reinforcement to occur either systematically or unsystematically on $G-G, G-R, R-G$, and $R-R$ trials. In the discrimination condition, all G-G and R-R trials involved food reinforcement, and all
G-R and $R-G$ trials involved nonreinforcement. In the nondiscrimination condition, a random half of $G-G, G-R, R-G$, and $R-R$ trials involved food reinforcement and nonreinforcement. The two experimental conditions thus differed only with respect to the correlation between the serial compound stimuli and food reinforcement; in either case, the expected number of G-G, G-R, $R-G$, and $R-R$ trials was 25 and the expected number of food reinforcements was 50 in a daily session. During experimental training, three birds were assigned to each of the treatment conditions.

Behavioral measures. The latency (in .1-sec units) of the first keypeck and total keypecks during the first $5 \mathrm{sec}$ of the firstpresented stimulus were recorded. Total key pecks during the 1 -sec interstimulus delay interval were measured, and the latency of the first keypeck and total keypecks during the first $5 \mathrm{sec}$ of the second-presented stimulus were recorded.

\section{Results}

All of the subjects pecked the two colors of key light during the autoshaping session and quickly came to peck the key at substantial rates during the first few sessions of experimental training.

In order to assess the degree of discrimination between matching and nonmatching serial compound stimuli, the mean overall rate of keypecking during the first $5 \mathrm{sec}$ of the second-presented stimulus on matching and nonmatching trials was computed daily. A discrimination ratio of nonmatching rate $\div$ matching rate was calculated over 4-day blocks and is shown in Figure 1. This ratio is at or near 1.0 when equal rates of keypecking are evidenced on matching and nonmatching trials. The ratio declines toward 0.0 as the rate of keypecking on matching trials exceeds the rate of keypecking on nonmatching trials. Figure 1 clearly shows that,

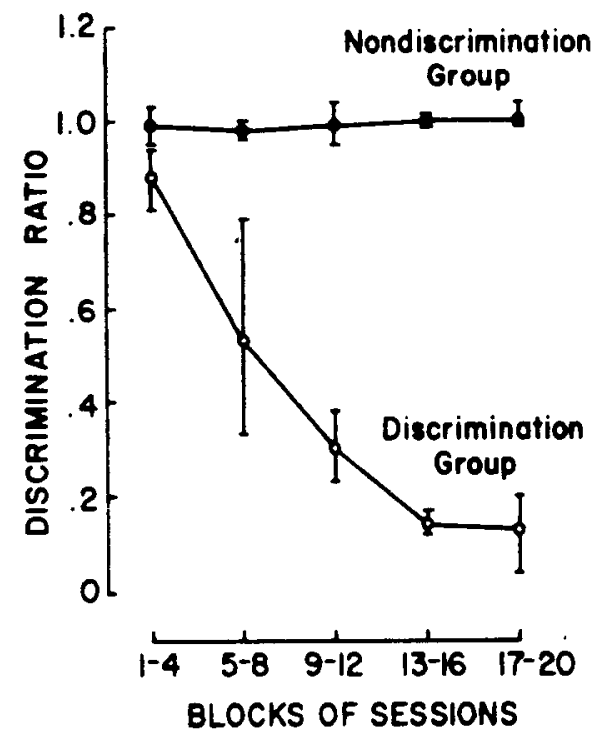

Figure 1. Mean and range of discrimination ratios of discrimination (Birds 1, 2, and 3) and nondiscrimination (Birds 4, 5 , and 6) groups over the first 20 days of experimental training. The discrimination ratio was rate of keypecking on nonmatching trials $\div$ rate of keypecking on matching trials. Keypecking rates were based on responding during the first $5 \mathrm{sec}$ of the second-presented stimulus. 
Table 1

Measures of Performance During the Second-Presented Stimulus During Days 17-20 of Training

\begin{tabular}{|c|c|c|c|c|c|c|}
\hline \multirow[b]{2}{*}{ Subject } & \multicolumn{2}{|c|}{$\begin{array}{l}\text { Mean Overall Rate } \\
\text { (pecks per sec) }\end{array}$} & \multicolumn{2}{|c|}{$\begin{array}{c}\text { Mean Latency } \\
(\mathrm{sec})\end{array}$} & \multicolumn{2}{|c|}{$\begin{array}{l}\text { Mean Running Rate } \\
\text { (pecks per sec) }\end{array}$} \\
\hline & Match & Nonmatch & Match & Nonmatch & Match & Nonmatch \\
\hline \multicolumn{7}{|c|}{ Discrimination Condition } \\
\hline $\begin{array}{c}1 \\
2 \\
3 \\
\text { Mean }\end{array}$ & $\begin{array}{r}.92 \\
1.58 \\
2.55 \\
1.68\end{array}$ & $\begin{array}{l}.04 \\
.32 \\
.40 \\
.25\end{array}$ & $\begin{array}{r}1.50 \\
.37 \\
.57 \\
.81\end{array}$ & $\begin{array}{l}4.60 \\
2.76 \\
3.24 \\
3.53\end{array}$ & $\begin{array}{l}1.31 \\
1.71 \\
2.86 \\
1.96\end{array}$ & $\begin{array}{r}.52 \\
.67 \\
1.07 \\
.75\end{array}$ \\
\hline \multicolumn{7}{|c|}{ Nondiscrimination Condition } \\
\hline $\begin{array}{c}4 \\
5 \\
6 \\
\text { Mean }\end{array}$ & $\begin{array}{l}2.21 \\
1.94 \\
2.49 \\
2.21\end{array}$ & $\begin{array}{l}2.29 \\
1.89 \\
2.46 \\
2.21\end{array}$ & $\begin{array}{l}.37 \\
.60 \\
.36 \\
.44\end{array}$ & $\begin{array}{l}.31 \\
.66 \\
.36 \\
.44\end{array}$ & $\begin{array}{l}2.39 \\
2.20 \\
2.68 \\
2.42\end{array}$ & $\begin{array}{l}2.44 \\
2.17 \\
2.65 \\
2.42\end{array}$ \\
\hline \multicolumn{7}{|c|}{ Discrimination* Condition } \\
\hline $\begin{array}{c}4 \\
5 \\
\text { Mean }\end{array}$ & $\begin{array}{l}1.12 \\
1.48 \\
1.30\end{array}$ & $\begin{array}{l}.10 \\
.25 \\
.18\end{array}$ & $\begin{array}{l}.87 \\
.38 \\
.63\end{array}$ & $\begin{array}{l}3.67 \\
1.86 \\
2.77\end{array}$ & $\begin{array}{l}1.35 \\
1.59 \\
1.47\end{array}$ & $\begin{array}{l}.36 \\
.39 \\
.38\end{array}$ \\
\hline
\end{tabular}

* For Birds 4 and 5, discrimination training followed nondiscrimination training.

during experimental training, nondiscrimination subjects (Birds 4, 5, and 6) keypecked at virtually equal rates during the second-presented stimulus on matching and nonmatching trials over the 20 days of training. On the other hand, discrimination subjects (Birds 1,2, and 3) rapidly learned to refrain from keypecking on nonmatching trials. Over Days 13-20, discrimination subjects keypecked at least five times more often on matching than on nonmatching trials.

An indication of stable performance under discrimination and nondiscrimination conditions can be gained by examination of keypecking during the last 4 days of experimental training. In addition to providing the mean overall rate of keypecking during the first $5 \mathrm{sec}$ of the second-presented stimulus on matching and nonmatching trials, Table 1 also partitions this overall measure into the mean latency of the first keypeck (a maximum score here would be $5.0 \mathrm{sec}$ ) and mean running rate of keypecking (here total keypecks are divided by total trial time minus total latency time). Discrimination subjects not only waited longer to begin keypecking on nonmatching trials than on matching trials, but also, even when they began keypecking on nonmatching trials, they keypecked at a lower rate than on matching trials. Both of these tendencies contributed to the higher overall rate of keypecking on matching than on nonmatching trials (see Figure 1 and Table 1). However, nondiscrimination subjects showed no consistent difference between matching and nonmatching trials on the basis of any of the performance measures.

In any investigation of memory in animals, the possibility that mediating chains of behavior are responsible for discriminative performance should be considered (see Blough, 1959). Frequent observation of discrimination subjects failed to reveal any stereotyped actions after green and red sample stimuli that would permit the birds later to perform discriminatively in the presence of the second stimulus of a pair. These observations were supported by examination of the birds' keypecking behavior during the interstimulus interval. The mean rate of keypecking (pecks per second) during the interstimulus interval after green and red samples was .05 vs. .05 , 1.11 vs. 1.10 , and .35 vs. .32 for Birds 1,2 , and 3 , respectively.

The possibility that sampling error or different preexperimental histories may have been responsible for performance differences between discrimination and nondiscrimination subjects was examined. After experimental training ended, Birds 4 and 5 were placed on the discrimination procedure for 20 days. Table 1 shows that these subjects also responded discriminatively to the second-presented stimulus on matching and nonmatching trials. Over Days 17-20, the mean discrimination ratios of Birds 4 and 5 were .09 and .17 , respectively.

\section{DISCUSSION}

The results reveal the applicability of Konorski's successive matching-to-sample memory task to avian subjects. Pigeons successfully discriminated matching and nonmatching serial color stimuli when a 1-sec interstimulus interval was employed. Furthermore, the acquisition of this discrimination was the direct result of the programmed experimental contingencies between the compound stimuli and reinforcement, since nondiscrimination control subjects failed to evidence differential performance on matching and nonmatching trials. There was no evidence to support the hypothesis that mediating behaviors were responsible for differential performance during the second stimulus of a trial pair.

Pigeons were able to master the complex discrimina- 
tions involved in this task within 2 weeks of training, despite the fact that no stagewise training procedures were employed (see Bradley \& Roberts, 1965; Chorazyna, 1959; Chorazyna \& Stepien, 1961; Stepien et al., 1960). The birds had seemingly less difficulty in forming the matching discriminations than did the dogs and monkeys in earlier investigations.

Discriminative performance during the secondpresented stimulus of a pair was manifested both as a longer latency to respond on nonmatching trials and as a lower rate of response, given that a response was emitted on nonmatching trials. Since the interstimulus interval was $1 \mathrm{sec}$ and the mean latency to keypeck was over $3 \mathrm{sec}$ for Birds 1, 2, 3, 4, and 5 on the discrimination procedure (see Table 1), it appears that the pigeons were "remembering" the color of the first stimulus for at least $4 \mathrm{sec}$. More analytical study of the scope of the pigeon's short-term memory with the successive-matching task is currently under investigation.

\section{REFERENCES}

Blough, D. S. Delayed matching in the pigeon. Journal of the Experimental Analysis of Behavior, 1959, 2, 151-160.

Bradley, P. B., \& Roberts, M. H. T. A method for studying the effects of drugs on recent memory in animals. In M. Ya. Mikel'son \& V. G. Longo (Eds.), Pharmacology of conditioning, learning and retention. Oxford: Pergamon Press, 1965.

Brown, P. L., \& Jenkins, H. M. Auto-shaping of the pigeon's key-peck. Journal of the Experimental Anahysis of Behavior, 1968, 11, 1-8.

Chorazyna, H. Investigation of recent memory of acoustic stimuli in normal dogs. Bulletin de l'Academie Polonaise des Sciences: Serie des Sciences Biologiques, 1959, 7, 119-121.

Chorazyna, H., \& Stepien, L. Impairment of auditory recent memory produced by cortical lesions in dogs. Acta Biologiae Experimentalis. Varsovie, 1961, 21, 177-187.
D'Aмато, M. R. Delayed matching and short-term memory in monkeys. In G. H. Bower (Ed.). The psychology of learning and motivation: Advances in research and theory. Vol. 7. New York: Academic Press, 1973.

D'Amato, M. R.. \& O'Neill, W. Matching behavior: Some methodological problems. Behavior Research Methods \& Instrumentation. 1970, 2. 162-164.

D'Amato, M. R., \& Worsham, R. W. Retrieval cues and shortterm memory in capuchin monkeys. Joumal of Comparative and Physiological Psychology, 1974, 86, 274-282.

Fletcher, H. J. The delayed response problem. In A. M. Schrier, H. F. Harlow, \& F. Stollnitz (Eds.), Behavior of nonhuman primates. New York: Academic Press, 1965.

Herman, L. M., \& Gordon, J. A. Auditory delayed matching in the bottlenose dolphin. Journal of the Experimental Analysis of Behavior, 1974, 21, 19-26.

HunTER, W. S. The delayed reaction in animals and children. Behavior Monographs, 1913, 2, 1-86.

KonORSKI, J. A. A new method of physiological investigation of recent memory in animals. Bulletin de l'Academie Polonaise des Sciences: Serie des Sciences Biologiques, 1959, 7, 115-119.

Roberts, M. H. T., \& Bradley. P. B. Studies on the effects of drugs on performance of a delayed discrimination. Physiology and Behavior, 1967. 2, 389-397.

SIEgel. S. Discrimination overtraining and shift behavior. In R. M. Gilbert \& N. S. Sutherland (Eds.), Animal discrimination learning. London: Academic Press, 1969.

Stepien, L. S., Cordeau, J. P., \& Rasmussen, T. The effect of temporal lobe and hippocampal lesions on auditory and visual recent memory in monkeys. Brain, 1960, 83, 470-489.

Urcuioli, P. J., \& Nevin, J. A. Transfer of hue matching in pigeons. Journal of the Experimental Analysis of Behavior. 1975, 24, 149-155.

Weiskrantz, L. Memory. In L. Weiskrantz (Ed.), Analysis of behavioral change. New York: Harper \& Row, 1968.

Zentall, T., \& Hogan, D. Abstract concept learning in the pigeon. Joumal of Experimental Psychology, 1974, 102, 393-398.

(Received for publication November 28, 1975; revision accepted January 20, 1976.) 